\title{
Mutual Influence of Energy Consumption and Foreign Direct Investment on Haze Pollution in China: a Spatial Econometric Approach
}

\author{
Dengli Tang ${ }^{1 *}$, Hui Xu ${ }^{1}$, Yuanhua Yang ${ }^{2}$ \\ ${ }^{1}$ School of Business Administration, Guangdong University of Finance and Economics, Guangzhou, China \\ ${ }^{2}$ Public Management School, Guangdong University of Finance and Economics, Guangzhou, China
}

Received: 5 July 2017

Accepted: 27 September 2017

\begin{abstract}
Based on the data of annual average values of $\mathrm{PM}_{10}$ concentrations in China, this study empirically investigates the spatial autocorrelation of haze pollution in China and the mutual influence of energy consumption and foreign direct investment on haze pollution in China from 2004 to 2014 using the spatial econometric method. Moran's I values are all above 0 during the 10 years, which indicates that haze pollution in China exists with significant spatial autocorrelation. Then the spatial econometric model estimation results show that energy consumption has a significant and positive effect on haze pollution in China while foreign direct investment has a significant and negative effect on haze pollution. Meanwhile, the regression coefficient of mutual variable of energy consumption and foreign direct investment is 0.063 at the $5 \%$ level, which suggests that foreign direct investment plays an important role in regulating the relationship between energy consumption and haze pollution, namely that the aggravation effect of energy consumption on haze pollution will increase with the increase of foreign direct investment. Finally, we provide some policy guidance for controlling haze pollution in China.
\end{abstract}

Keywords: haze pollution, energy consumption, foreign direct investment, spatial econometric method, exploratory spatial data analysis

\section{Introduction}

Air pollution has been one of the greatest challenges all over the world. As the biggest developing country, China undergoes severe environmental pollution due to its continuously increasing economy [1-2]. Under the dual drive of environmental pollution and economic development, the urban air pollution problem has

*e-mail: tangdengli_2008@163.com gradually become the core topic most likely to be the bottleneck of sustainable development. Since winter 2012, severe extreme haze events have occurred in northern and eastern China - especially in the cityclusters such as the Beijing-Tianjin-Hebei area, Yangtze River Delta area, and Pearl River Delta area [3-4]. Haze occurs when sunlight is absorbed and scattered by high concentrations of atmospheric aerosols [5]. It not only has a direct depressive mental effect on human beings, but also alters the ecological system and climate [67]. Thus, research on the influential factors of haze pollution will provide meaningful insights for controlling 
haze pollution, ensuring people's health and promoting economic development.

Numerous research has investigates the related problem of haze pollution from the socioeconomic perspective, such as causes, spatial correlation, harm, and influence factors of haze pollution. For instance, Wang et al. (2014) pointed out that the external cause of the severe haze episodes is the unusual atmospheric circulation and the depression of strong cold air activities, and the internal cause is the quick secondary transformation of primary gaseous pollutants to secondary aerosols [8]. Many existing studies also have focused on the temporal and spatial distribution of haze pollution and examined its spatial spillover effect. For example, Wang et al. (2012) showed that haze events have a very similar and clear seasonal variation [5]. Tang et al. (2016) suggested that haze pollution in China has a strong spatial clustering phenomenon and spatial spillover effects [9]. Meanwhile, some scholars have indicated that the haze crisis can cause enormous harm to the environment, people's lives and health, and economic activities [10-11]. Recently, influence factors of haze pollution have been a focus of many studies $[6,9,12]$. Based on panel data of 31 provinces' annual averaged $\mathrm{PM}_{2.5}$ concentrations over the period 2000-2012, Tang et al. (2016) found a significantly positive relationship between FDI and haze pollution in China [9]. Ma and Zhang (2014) also suggested that optimizing energy consumption structure will play a key role in controlling haze in the long run, and that reducing coal consumption can solve the haze problem in the short term [12]. Hao and Liu (2016) suggested that the relationship between $\mathrm{PM}_{2.5}$ concentrations and per capita GDP is an inverted U-shaped, and vehicle population and secondary industry have significant and positive influences on urban $\mathrm{PM}_{2.5}$ concentrations [6].

In fact, some existing studies have verified the relationship of energy consumption and foreign direct investment [13-15]. For example, He (2006) examined industrial sulfur dioxide $\left(\mathrm{SO}_{2}\right)$ emissions for 29 Chinese provinces and showed that the total impact of foreign direct investment on industrial $\mathrm{SO}_{2}$ emissions is very small. With a $1 \%$ increase in FDI capital stock, industrial $\mathrm{SO}_{2}$ emissions will increase by $0.098 \%$ [16]. By using macro level data on 60 developing countries for the period 19752004, Huebler and Keller (2010) did not confirm that FDI inflows reduce energy intensities of developing countries in general [14]. Based on a unique dataset of 206 of the largest prefecture-level cities between 2005 and 2008, Elliott et al. (2013) investigated the relationship between energy intensity of Chinese cities and the location of foreign firms, and found evidence of a significant and negative relationship between foreign direct investment flows into a city and energy intensity [17].

Therefore, under normal circumstances, energy consumption and foreign direct investment are not alone in the process of affecting haze pollution as foreign direct investment can affect energy consumption intensity and energy consumption efficiency in many ways. The expansion of foreign direct investment will facilitate the introduction of advanced technology, equipment, and managerial experience, in which it will increase energy efficiency and the international liquidity of elements to the outside world. That is to say, foreign direct investment has an adjustment influence on the relationship of energy consumption and haze pollution.

Although previous studies have verified the relationship of foreign direct investment and energy consumption, few studies have been conducted to investigate the mutual influence of energy and foreign direct investment on haze pollution in China. Therefore, this paper aims to at least partially fill this gap in the literature by investigating the mutual influence of energy consumption and foreign direct investment on haze pollution in China using the data of annual average values of $\mathrm{PM}_{10}$ concentrations in China from 2004 to 2014. This study not only examines the spatial autocorrelation of haze pollution in China, but also reveals the mutual influence of energy consumption and foreign direct investment on haze pollution in China from the angle of a spatial relationship.

Therefore, the aims of this paper were to:

1) Estimate the spatial autocorrelation of haze pollution in China using the exploratory spatial data analysis method.

2) Investigate the mutual effect of energy consumption and foreign direct investment on haze pollution in China using spatial econometric models, including spatial lag model (SLM) and spatial error model (SEM).

\section{Material and Methods}

\section{Data Sources}

We estimated the mutual influence of energy consumption and foreign direct investment on haze pollution by using panel data of China's 30 provinces between 2004 and 2014. All the original data are collected from the National Statistical Yearbook (2005-2015) and China Environment Yearbook (2005-2015). To address missing data, we complemented this database with China Statistical Yearbook for Regional Economy (2005-2015). In order to eliminate heteroscedasticity, all variables are transformed into the natural logarithm form.

\section{Variable Descriptions}

\section{Haze Pollution}

Considering the fact that particulate matter is the main component of haze pollution in China $[4,6], \mathrm{PM}_{10}$ or $\mathrm{PM}_{2.5}$ concentrations will be used as dependent variables. Meanwhile, as partial cities have begun to report $\mathrm{PM}_{2.5}$ concentrations since 2012, the annual average values of $\mathrm{PM}_{10}$ concentrations are utilized in this study. In addition, all data for the annual average values of $\mathrm{PM}_{10}$ concentrations in China Statistical Yearbook are based on provincial capital cities. Considering that haze pollution 
exists in the spatial spillover effect and that provincial capital cities are often the focus of the entire province's economic activities, this paper uses annual average values of $\mathrm{PM}_{10}$ concentrations of provincial capital cities to replace the annual average values of $\mathrm{PM}_{10}$ concentrations of the whole province according to Wang and $\mathrm{Xu}$ (2015) [18].

\section{Gross Domestic Product}

Gross domestic product (GDP) is used to measure the level of economic growth in this paper. GDP can reflect a region's economic growth level, and the environmental pollution problem is related to economic growth. Grossman and Krueger (1995) found an inverted U-shaped relationship between the economy and environmental pollution, which is called EKC [19]. Therefore, in order to obtain more accurate estimation results, this paper estimates the relationship of economic growth and haze pollution by setting GDP and GDP squared.

\section{Energy Consumption}

The level of energy consumption (EC) is measured by total energy consumption, which reflects a region's economic development degree. At present, the second industry still accounts for a high proportion in China's industrial structure, and this circumstance will aggravate China's environmental pollution. Many scholars have studied energy consumption problems, such as Peng and He (2015) [20] and Hu and Liu (2015) [21]. Due to total energy consumption reflecting the level of regional energy consumption more directly, this paper uses total energy consumption as an indicator of energy consumption.

\section{Foreign Direct Investment}

Foreign direct investment (FDI) is measured by regional actual utilized FDI. On the one hand, developed countries tend to transfer pollution-intensive industries to developing countries with laxer environmental regulations in order to gain lower labor costs and competitiveness. On the other hand, developing countries can also study advanced production technology and management experience through technology spillover effect from developed countries. In a word, the comprehensive influence of FDI on environment pollution depends on multiple-effects. Table 1 presents descriptive statistics for variables.

\section{Exploratory Spatial Data Analysis Method}

In this paper, we first investigate the spatial autocorrelation of haze pollution using the exploratory spatial data analysis method, which is used to detect cluster pattern phenomenon in the entire study area [22]. Spatial correlation can be measured by Moran's I statistics, and Moran's I value is expressed as:

$$
I=\frac{n \sum_{i} \sum_{j \neq i} w_{i j}\left(y_{i}-\bar{y}\right)\left(y_{j}-\bar{y}\right)}{\sum_{i} \sum_{j \neq i} w_{i j} \sum_{i}\left(y_{i}-\bar{y}\right)^{2}}
$$

...where $\mathrm{y}_{\mathrm{i}}$ and $\mathrm{y}_{\mathrm{j}}$ are annual average values of $\mathrm{PM}_{10}$ concentrations, respectively, and $\mathrm{w}_{\mathrm{ij}}$ is the spatial weights matrix. Generally, Moran's I values range from -1 to 1 . A positive Moran's I value means positive spatial correlation; a negative value indicates negative autocorrelation.

\section{Model Specification}

Spatial econometric models can be considered the extensions of conventional econometric models by adding a spatial variable. According to the research of Anselin (1995) [23], we use spatial econometric models, including SLM and SEM, to estimate the mutual influence of energy consumption and foreign direct investment on haze pollution. Early scholars such as Grossman and Krueger (1995) found an inverted U-shaped relationship between the economy and environmental pollution, which is called EKC [19]. Therefore, the basic econometric model-based $\mathrm{EKC}$ is shown below:

$$
\ln Y_{i}=\beta_{0}+\beta_{1} \operatorname{lnGDP} i+\beta_{2} \ln ^{2} \mathrm{GDP}_{\mathrm{i}}+\beta_{3} \ln \mathrm{X}_{\mathrm{i}}+\varepsilon_{\mathrm{i}}
$$

...where Y is the dependent variable; GDP is gross domestic product; $\varepsilon$ is the disturbance term; and $\mathrm{X}$ denotes other independent variables, including energy consumption, foreign direct investment, and the mutual term of energy consumption and foreign direct investment.

When spatial correlation exists, the conventional econometric model estimation will lead to invalid results. SLM assumes that spatial correlation stems from dependent variables; SEM assumes that spatial correlation stems from the error shock of adjacent regions on dependent variables. According to the definitions, the SLM and SEM models can be written as:

Table 1. Descriptive statistics for variables.

\begin{tabular}{|c|c|c|c|c|c|}
\hline Variables & Unit & Min & Max & Mean & Std. Dev. \\
\hline $\ln Y$ & $\mathrm{ug} / \mathrm{m}^{3}$ & 3.497 & 5.720 & 4.607 & 0.304 \\
\hline $\ln \mathrm{GDP}$ & 100 million yuan & 6.145 & 10.893 & 8.903 & 0.955 \\
\hline $\ln ^{2} \mathrm{GDP}$ & 100 million yuan & 37.756 & 118.653 & 80.166 & 16.542 \\
\hline $\operatorname{lnEC}$ & 1,000 tce & 6.609 & 10.617 & 9.152 & 0.743 \\
\hline $\operatorname{lnFDI}$ & 100 million yuan & 0.492 & 7.410 & 4.834 & 1.647 \\
\hline
\end{tabular}




$$
\begin{gathered}
\ln \mathrm{Y}_{\mathrm{i}}=\rho \mathrm{w} \ln \mathrm{Y}_{i}+\beta_{0}+\beta_{1} \operatorname{lnGDP_{i}}+\beta_{2} \ln ^{2} \mathrm{GDP}_{\mathrm{i}}+ \\
+\beta_{3} \ln \mathrm{X}_{\mathrm{i}}+\varepsilon_{\mathrm{i}}
\end{gathered}
$$

$$
\begin{gathered}
\ln \mathrm{Y}_{\mathrm{i}}=\beta_{0}+\beta_{1} \operatorname{lnGDP_{\mathrm {i}}}+\beta_{2} \ln ^{2} \mathrm{GDP}_{\mathrm{i}}+\beta_{3} \ln \mathrm{X}_{\mathrm{i}}+\varepsilon_{\mathrm{i}}, \\
\varepsilon_{\mathrm{i}}=\lambda w \ln \mathrm{Y}_{\mathrm{i}}+u
\end{gathered}
$$

...where Equations (3) and (4) denote SLM and SEM, respectively; wlnY is the spatial lag variable; $\rho$ is the spatial autoregressive coefficient; $\lambda$ is spatial error autoregressive coefficient; and $\mathrm{w}$ is the spatial weight matrix.

\section{Results and Discussion}

\section{Results and Analysis of Spatial Autocorrelation Test}

According to the results of Moran's I statistics of haze pollution in China, Moran's I values are all above 0 . And all years' Moran's I values are significant at the 0.1 significance level except 2004, indicating that haze pollution exists as spatial autocorrelation. Meanwhile, Moran's I values are increasing year by year from 2004 to 2014, suggesting that spatial autocorrelation haze pollution in China strengthened gradually. That is to say, these regions with high haze pollution are usually adjacent to these regions with high haze pollution, and these regions with low haze pollution are usually adjacent to these regions with low haze pollution.

Although Moran's I values illustrate the spatial autocorrelation of haze pollution, Moran's I scatterplot also is a visual tool to illustrate spatial autocorrelation intuitively [24]. Fig. 1 presents Moran scatterplots of $\mathrm{PM}_{10}$ in 2004, 2009, and 2014. As shown in Fig. 1, most provinces are located in the high-high and low-low quadrants, suggesting the existence of similar clustering characteristics. In other words, it means that highly polluted provinces tend to be adjacent to highly polluted provinces, and vice versa.

\section{Results and Analysis of Spatial Econometric Model}

In order to choose which spatial econometric model is more appropriate, we first evaluate the model using the conventional OLS method, and then analyze spatial econometric model estimation results. To assess the mutual influence of energy consumption and foreign direct investment on haze pollution in China, we introduce four models by adding independent variables into Equation (3). Variables EC and FDI in logarithmic form are respectively added in the first and second models, variable EC is added in the third model along with variable FDI, and the mutual variable of EC and FDI is added in the fourth model. The estimation results of OLS are presented in Table 2.

The LM values and robust LM values can decide which spatial econometric model is a better choice. As shown in Table 2, the p values of LM tests are 0.000 for the four models, and LM values for SLM and SEM are high and close. Therefore, we further compare the robust LM values. The robust LM values for SEM are significant at the 0.01 significance level for the four models, and the robust LM values for SLM are not significant for the four models. Thus, the results suggest that SEM is more appropriate than SEM.

Although LM values and robust LM values from OLS can decide which spatial econometric model is more appropriate, OLS may yield biased estimation results because of the existence of spatial correlation [1]. In Table 2, Moran's I values have confirmed spatial autocorrelation of haze pollution in China, so this paper establishes SLM and SEM to investigate the mutual influence of energy consumption and foreign direct investment on haze pollution in China. Moreover, Elhorst (2003) pointed out that when sample regression analysis is limited to certain individuals, the fixed effect model is a better choice [25]. Thus, this paper uses spatial lag fixed effect and spatial error fixed effect to analyze mutual influence, including spatial fixed effect (SFE), time fixed effects (TFE), and spatial and time fixed effect (STFE). The estimation results of SLM and SEM are shown in Tables 3 and 4, respectively.
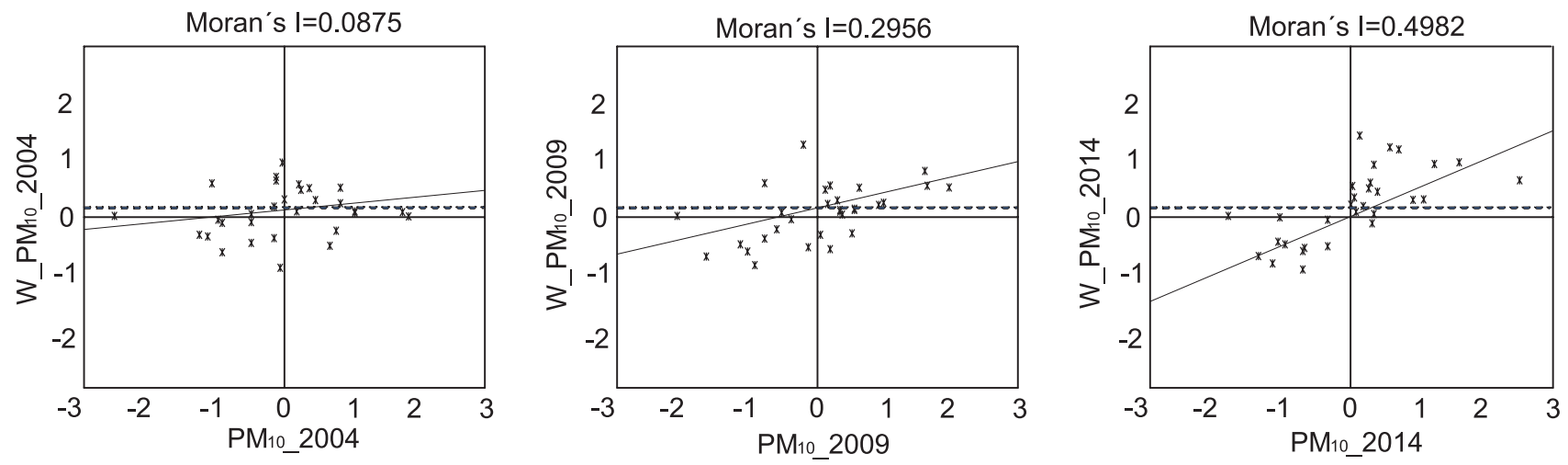

Fig. 1. Moran's I scatterplots for $\mathrm{PM}_{10}$ in 2004, 2009, and 2014. 
Table 2. Estimation results of OLS.

\begin{tabular}{|c|c|c|c|c|}
\hline Variables & Model 1 & Model 2 & Model 3 & Models 4 \\
\hline \multirow{2}{*}{ Constant } & $2.852 * * *$ & $3.668 * * *$ & $2.925 * * *$ & $2.713 * * *$ \\
\hline & (3.067) & (3.849) & $(3.151)$ & $(2.722)$ \\
\hline \multirow{2}{*}{$\operatorname{lnGDP}$} & $0.782 * * *$ & $0.445^{* *}$ & $0.689 * * *$ & $0.824 * * *$ \\
\hline & $(3.432)$ & (2.583) & $(2.982)$ & (3.479) \\
\hline \multirow{2}{*}{$\ln ^{2} \mathrm{GDP}$} & $-0.036 * * *$ & $-0.026^{*}$ & $-0.028 * *$ & $-0.049 * * *$ \\
\hline & $(-2.804)$ & $(-1.896)$ & $(-2.139)$ & $(-3.061)$ \\
\hline \multirow{2}{*}{$\operatorname{lnEC}$} & $0.288 * * *$ & & $0.248 * * *$ & $0.215 * * *$ \\
\hline & $(6.924)$ & & (5.208) & (4.864) \\
\hline \multirow{2}{*}{$\operatorname{lnFDI}$} & & $-0.082 * * *$ & $-0.033^{*}$ & $-0.057 * *$ \\
\hline & & $(-4.723)$ & $(-1.727)$ & $(-2.699)$ \\
\hline \multirow{2}{*}{$\operatorname{lnEC} * \operatorname{lnFDI}$} & & & & $0.055^{* *}$ \\
\hline & & & & $(2.588)$ \\
\hline $\mathrm{R}^{2}$ & 0.152 & 0.089 & 0.160 & 0.161 \\
\hline DW & 1.058 & 1.093 & 1.053 & 1.046 \\
\hline $\log L$ & -47.082 & -58.799 & -45.574 & -45.398 \\
\hline Moran's I & $12.783 * * *$ & $13.819 * * *$ & $13.098 * * *$ & 13.216 \\
\hline LM lag & $149.775^{* * *}$ & $151.490 * * *$ & $153.219^{* * *}$ & $155.551 * * *$ \\
\hline Robust LM lag & 0.102 & 0.129 & 0.032 & 0.139 \\
\hline LM error & $156.961 * * *$ & $161.489 * * *$ & $164.259 * * *$ & $167.698 * * *$ \\
\hline Robust LM error & $7.288 * * *$ & $10.929 * * *$ & $11.071 * * *$ & $12.286^{* * *}$ \\
\hline
\end{tabular}

Note: Figures in parentheses are t-statistics; $* * *, * *$, and $*$ indicate the significance at $1 \%, 5 \%$, and $10 \%$ levels, respectively.

As shown in Tables 3 and 4, the $\mathrm{R}^{2}$ values and $\log$ likelihood $(\log L)$ values of spatial fixed effect are bigger than the other three fixed effects for the four models. Meanwhile, LM tests suggest that SEM is more appropriate for the four models, indicating that the change of haze pollution in a province will affect its adjacent provinces. Therefore, for the four models, spatial fixed effect of SEM is chosen to estimate the mutual influence of energy consumption and foreign direct investment on haze pollution.

First, it is noteworthy that all of the spatial autoregressive coefficients $\rho$ and spatial error autoregressive coefficients $\lambda$ in SLM and SEM are positive and statistically significant at the $1 \%$ level, indicating that haze pollution exists as spatial dependence. In spatial fixed effect of SEM, $\lambda$ values are, respectively, 0.717, $0.740,0.726$, and 0.730 for models $1-4$, which means that an increase of $1 \%$ in one region's haze pollution will cause a $0.717 \%$ rise in haze pollution of its adjacent regions for model 1 (other models being equal). It also means that haze pollution has a strong spatial spillover effect in China, and the highly (low) polluted provinces tend to be adjacent to highly (low) polluted provinces. These results are basically consistent with the conclusions of Moran scatterplots in Fig. 1.
Model 1 is used to test the relationship of energy consumption and haze pollution in China. Table 4 shows that the regression coefficient of energy consumption is statistically significant at the $1 \%$ level. This means that the higher energy consumption is more likely to cause higher haze pollution. Therefore, solving the problem of energy consumption and haze pollution is urgently needed. Regional government should control the total of energy consumption, promote industry access requirement, and develop cleaner energy such as renewable and gas energy. In addition, the regression coefficients of GDP are significant, namely with GDP increases, the degree of haze pollution first increased, then decreased.

Model 2 is used to evaluate the relationship of foreign direct investment and haze pollution in China. In model 2, the regression coefficients of foreign direct investment are negative, indicating that the increase of foreign direct investment helps decrease haze pollution in China, which supports pollution halo hypothesis. There may be two reasons: first, with the enhancement of environmental protection awareness, some regions prefer foreign companies with advanced production technology and clean technology in order to improve environmental quality; second, foreign direct investment 


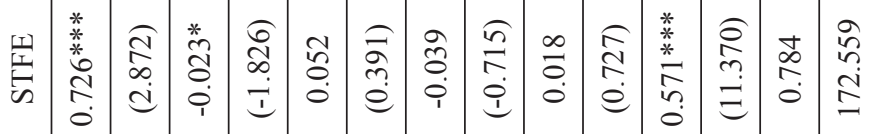

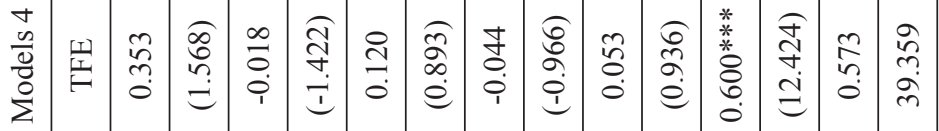

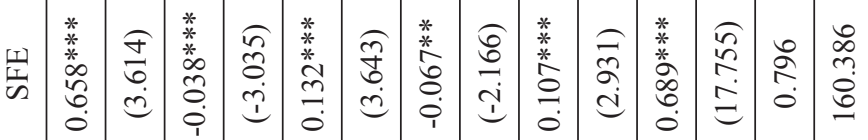

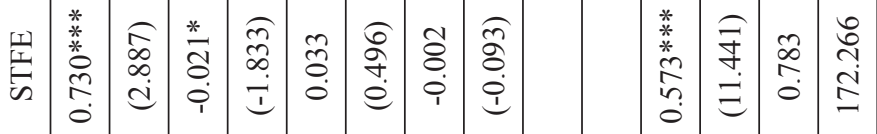

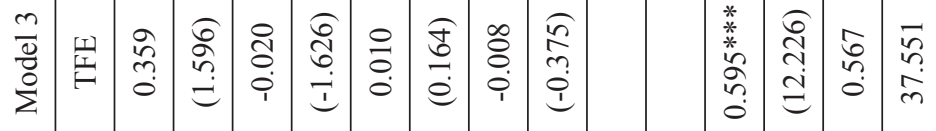

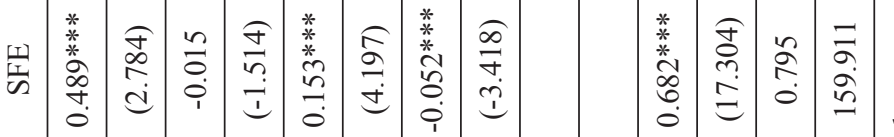

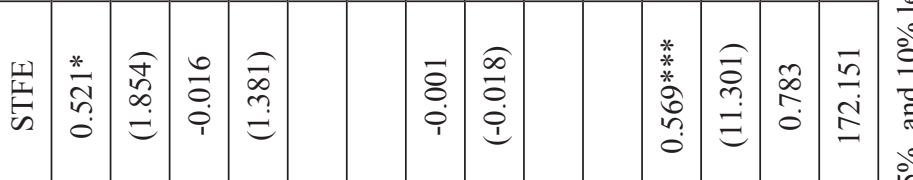

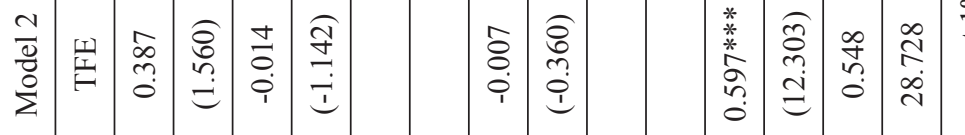

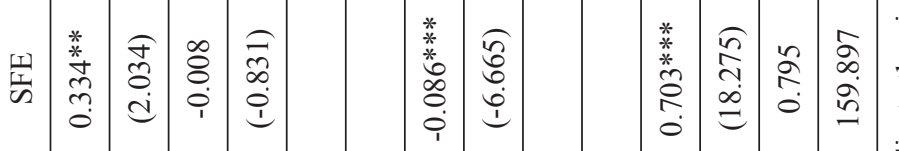

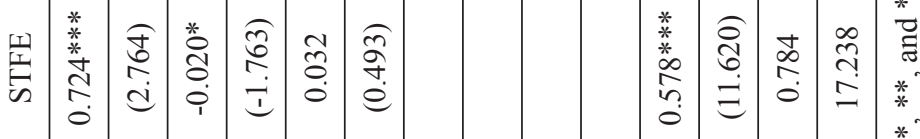

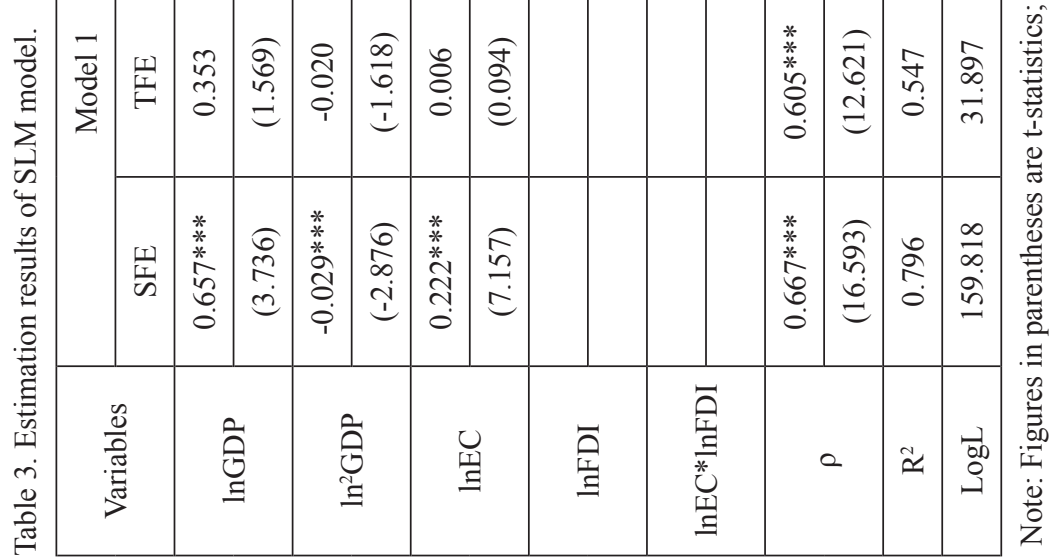




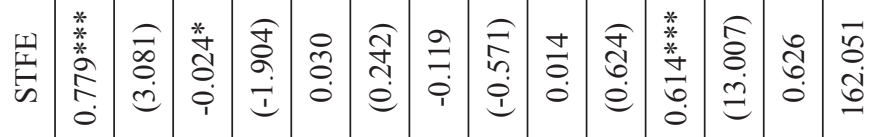

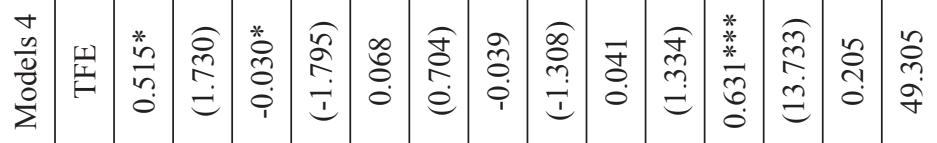

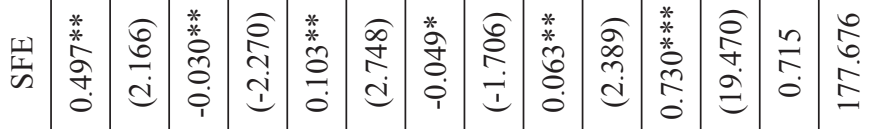

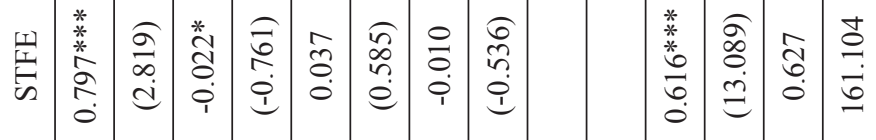

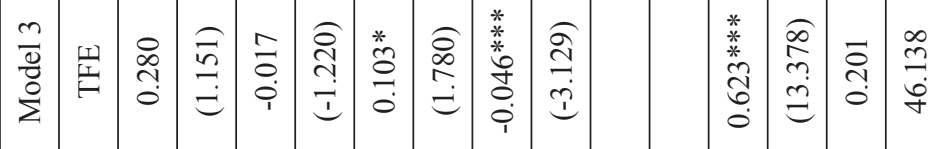

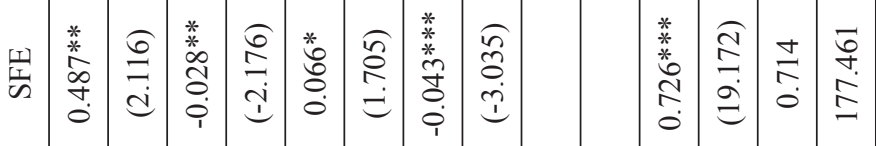

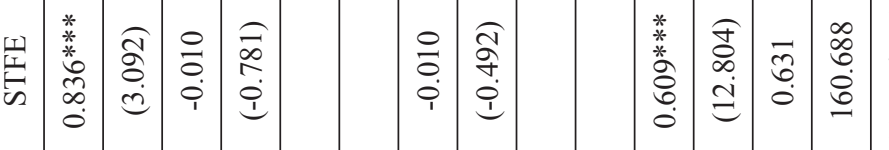

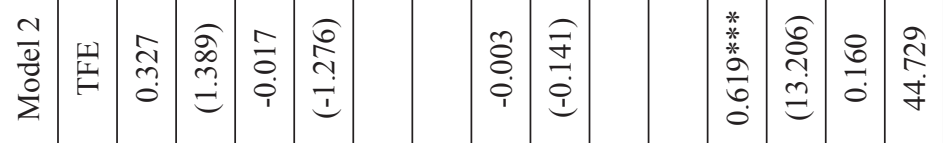

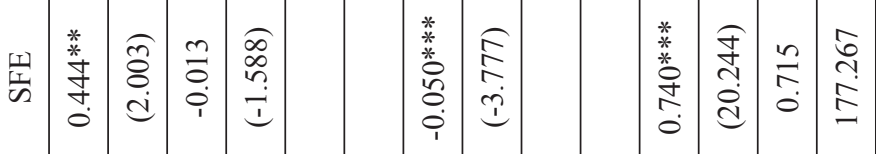

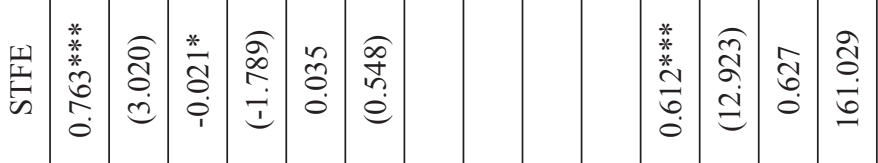

\begin{tabular}{|c|c|c|c|c|c|c|c|c|c|c|c|c|c|}
\hline \multirow[t]{2}{*}{ 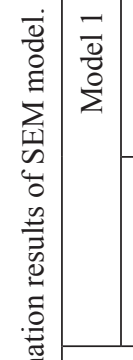 } & 突 & $\stackrel{\infty}{\stackrel{\infty}{0}}$ & $\left|\begin{array}{|c|}\stackrel{\widehat{\beth}}{\Xi} \\
\stackrel{\Xi}{\Xi}\end{array}\right|$ & $\mid \begin{array}{l}0 \\
\delta \\
0 \\
i \\
1\end{array}$ & 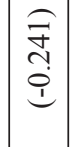 & $\begin{array}{l}\stackrel{*}{0} \\
\stackrel{0}{O} \\
\stackrel{0}{0}\end{array}$ & 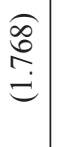 & & & 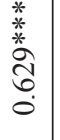 & 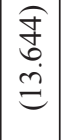 & $\stackrel{\infty}{=}$ & $\frac{\underset{f}{J}}{\stackrel{f}{+}}$ \\
\hline & 峠 & 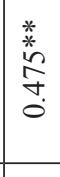 & $\mid \begin{array}{l}\hat{\sigma} \\
\dot{d} \\
\dot{d}\end{array}$ & 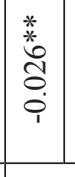 & $\begin{array}{c}\stackrel{\sigma}{o} \\
\stackrel{i}{i} \\
i\end{array}$ & 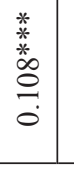 & $\begin{array}{l}\widehat{\infty} \\
\hat{\tilde{d}} \\
\underline{d}\end{array}$ & & & 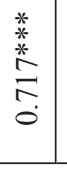 & $\begin{array}{l}\widehat{\approx} \\
\tilde{n} \\
\infty \\
\triangleq\end{array}$ & $\stackrel{\stackrel{2}{*}}{i}$ & 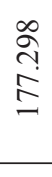 \\
\hline & 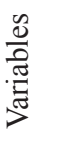 & & 苚 & 氕 & כ) & 琶 & & $\underset{\Xi}{\overrightarrow{I_{I}}}$ & 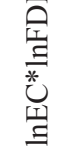 & 2 & ₹ & $\approx$ & $\begin{array}{l}\overrightarrow{0} \\
0 \\
\\
\end{array}$ \\
\hline
\end{tabular}


Table 5. Estimation results of SLM and SEM models.

\begin{tabular}{|c|c|c|c|c|c|c|}
\hline \multirow{2}{*}{ Variables } & \multicolumn{3}{|c|}{ SLM } & \multicolumn{3}{|c|}{ SEM } \\
\hline & SFE & TFE & STFE & SFE & TFE & STFE \\
\hline \multirow{2}{*}{$\operatorname{lnGDP}$} & $0.612 * * *$ & 0.254 & $0.640 * * *$ & $0.491 * *$ & 0.485 & $0.635^{* * *}$ \\
\hline & (2.779) & $(0.372)$ & $(3.000)$ & (2.109) & $(0.795)$ & (2.986) \\
\hline \multirow{2}{*}{$\ln ^{2} \mathrm{GDP}$} & $-0.038 * *$ & -0.017 & $-0.041 * * *$ & $-0.030 * *$ & -0.015 & $-0.023 *$ \\
\hline & $(-2.578)$ & $(-0.444)$ & $(-2.926)$ & $(-2.270)$ & $(-0.449)$ & $(-1.861)$ \\
\hline \multirow{2}{*}{$\operatorname{lnEC}$} & $0.309 *$ & 0.350 & 0.301 & $0.327 * *$ & $0.477 * *$ & $0.428^{*}$ \\
\hline & (1.696) & (1.486) & $(1.265)$ & (2.114) & $(2.214)$ & (1.954) \\
\hline \multirow{2}{*}{$\operatorname{lnFDI}$} & $-0.785^{* *}$ & -0.632 & -0.585 & $-0.702 * *$ & $-0.954 * *$ & $-0.866^{* *}$ \\
\hline & $(-2.504)$ & $(-1.442)$ & $(-1.318)$ & $(-2.537)$ & $(-2.380)$ & $(-2.112)$ \\
\hline \multirow{2}{*}{$\operatorname{lnEC} * \ln F D I$} & $0.080 * *$ & 0.070 & 0.065 & $0.071 * *$ & $0.105 * *$ & $0.096^{* *}$ \\
\hline & $(2.320)$ & (1.479) & (1.369) & $(2.362)$ & $(2.405)$ & (2.148) \\
\hline \multirow{2}{*}{$\rho / \lambda$} & $0.737 * * *$ & $0.645 * * *$ & $0.636^{* * *}$ & $0.765^{* * *}$ & $0.670 * * *$ & $0.679 * * *$ \\
\hline & $(16.868)$ & (11.557) & (11.238) & $(17.892)$ & $(12.490)$ & $(12.886)$ \\
\hline $\mathrm{R}^{2}$ & 0.791 & 0.617 & 0.784 & 0.664 & 0.204 & 0.594 \\
\hline $\log L$ & 99.867 & 28.971 & 95.371 & 101.316 & 35.489 & 96.569 \\
\hline Moran's I & $11.901 * * *$ & & & & & \\
\hline LM lag & $126.605 * * *$ & & & & & \\
\hline Robust LM lag & 0.000 & & & & & \\
\hline LM error & $134.224 * * *$ & & & & & \\
\hline Robust LM error & $7.619 * * *$ & & & & & \\
\hline
\end{tabular}

Note: Figures in parentheses are t-statistics; $* * *, * *$, and $*$ indicate the significance at $1 \%, 5 \%$, and $10 \%$ levels, respectively

tends to use more advanced green skills or clean production technology in the process of actual operation.

Model 3 extends model 1 by adding the independent variable of foreign direct investment. The regression results show that all three independent variables (GDP, energy consumption, foreign direct investment) have a significant relationship with haze pollution, and the results are consistent with models 1 and 2. In model 3, the regression coefficients of energy consumption are significant at the $10 \%$ level, and foreign direct investment's regression coefficient are significant at the $1 \%$ level, indicating that the impacts of energy consumption and foreign direct investment on haze pollution are opposite. Meanwhile, the absolute value of energy consumption coefficient is greater than the absolute value of foreign direct investment coefficient, implying that the aggravation effect of energy consumption on haze pollution exceeds the improvement effect of foreign direct investment on haze pollution.

Model 4 adds another independent variable, EC*FDI, which is the mutual term of energy consumption and foreign direct investment. The estimation results shows that the impacts of energy consumption and foreign direct investment on haze pollution are the same as models 1, 2, and 3. Meanwhile, the regression coefficient of mutual variable is 0.063 at the $5 \%$ level, meaning that foreign direct investment has an adjustment effect for the relationship of energy consumption and haze pollution. In other words, the aggravation effect of energy consumption on haze pollution will increase with the increase of foreign direct investment. Therefore, in order to reduce the aggravation effect of energy consumption on haze pollution, regions should give priority to companies with advanced production technology and clean technology in China while importing foreign direct investment.

\section{Robustness Test}

In order to test the stability of mutual effect between consumption and foreign direct investment, this study conducts a robustness test based on the data during 20082014, and the estimation results are listed in Table 5. As shown in Table 5, the relationship of energy consumption, foreign direct investment, and the mutual terms of energy consumption and foreign direct investment and haze pollution are coincident with the above results, namely that the impact of energy consumption and mutual variable on haze pollution are positive, and the impact of foreign direct investment on haze pollution is negative. 


\section{Conclusions}

This study investigated the mutual influence of energy consumption and foreign direct investment on haze pollution in China using the spatial econometric approach. Moran's I values and Moran's scatterplots confirm the existence of spatial autocorrelation of haze pollution. Then we used spatial econometric models, including SLM and SEM, to investigate the mutual effect of energy consumption and foreign direct investment on haze pollution.

The estimation results suggest that energy consumption contributes positively and significantly to haze pollution. So, the policy implications are straightforward: to efficiently decrease haze pollution, all regions should control the total of energy consumption and strengthen the development and utilization of cleaner energy such as renewable and gas energy. Besides, local governments should be strictly the management access standard of related industries in order to come true to the road of low-energy consumption and low pollution. In addition, China should speed up the adjustment of industrial structure and decrease the dependence degree on secondary industry.

In addition, the estimation results also demonstrate that foreign direct investment helps reduce haze pollution in China, and the pollution haven hypothesis is not supported in China. Therefore, China should not only continue the introduction of foreign capital, but also offer different investment policy guidance combined with our own economic development level and haze pollution situation, pay special attention to advanced green technology and clean production technology. Meanwhile, local governments need to formulate strict environmental access standards to introduce foreign investment with high benefit and high quality. In addition, China needs to establish an effective incentive mechanism for some behaviors such as technical innovation and environmental protection.

When a mutual variable is added in model 4, energy consumption and foreign direct investment still have positive and negative effects on haze pollution, respectively, and the impact degree of energy consumption on haze pollution is greater than the influence degree of energy consumption on haze pollution. Meanwhile, the impact of mutual variable of energy consumption and foreign direct investment on haze pollution is positive. Therefore, governments need to continue introducing foreign direct investment with clean production technology. Haze pollution is a long-term and arduous task, and control measures cannot stop. At the same time, atmospheric pollution treatment experience from other countries also should be learned, such as setting up a regional environmental management agency, signing and participating in regional environmental treaties, and so on.

\section{Acknowledgements}

This study was supported by the National Natural Science Foundation of China (No. 41361029).

\section{References}

1. LI Q., SONG J., WANG E., HU H., ZHANG J., WANG Y. Economic growth and pollutant emissions in China: a spatial econometric analysis. Stoch. Env. Res. Risk. A. 28 (2), 429, 2014.

2. REN S., YUAN B., MA X., CHEN X. International trade, FDI (foreign direct investment) and embodied $\mathrm{CO}_{2}$ emissions: a case study of Chinas industrial sectors. China. Econ. Rev. 28, 123, 2014.

3. CHENG Z., WANG S., JIANG J., FU Q., CHEN C., XU B., YU J., FU X., HAO J. Long-term trend of haze pollution and impact of particulate matter in the Yangtze River Delta, China. Environ. Pollut. 182, 101, 2013.

4. VAN DONKELAAR A., MARTIN R.V., BRAUER M., KAHN R., LEVY R., VERDUZCO C., VILLENEUVE P.J. Global estimates of ambient fine particulate matter concentrations from satellite-based aerosol optical depth: development and application. Environ. Health. Persp. 118 (6), 847, 2010.

5. WANG L., XU J., YANG J., ZHAO X., WEI W., CHENG D., PAN X., SU J. Understanding haze pollution over the southern Hebei area of China using the CMAQ model. Atmos. Environ. 56, 69, 2012.

6. HAO Y., LIU Y. influential factors of urban $\mathrm{PM}_{2.5}$ concentrations in China: a spatial econometric analysis. J. Clean. Prod. 112, 1443, 2016.

7. TAO M., CHEN L., WANG Z., MA P., TAO J., JIA S. A study of urban pollution and haze clouds over northern China during the dusty season based on satellite and surface observations. Atmos. Environ. 82, 183, 2014.

8. WANG Y., YAO L., WANG L., LIU Z., JI D., TANG G., ZHANG J., SUN Y., HU B., XIN J. Mechanism for the formation of the January 2013 heavy haze pollution episode over central and eastern China. Sci. China. Earth. Sci. 57 (1), 14, 2014.

9. TANG D., LI L., YANG Y. Spatial econometric model analysis of foreign direct investment and haze pollution in china. Pol. J. Environ. Stud. 25(1), 317, 2016.

10. ZHA Y., GAO J., JIANG J., LU H., HUANG J. Normalized difference haze index: a new spectral index for monitoring urban air pollution. Int. J. Remote. Sens. 33 (1), 309, 2012.

11. ZHANG Z., WANG J., CHEN L., CHEN X., SUN G., ZHONG N., KAN H., LU W. Impact of haze and air pollution-related hazards on hospital admissions in Guangzhou, China. Environ. Sci. Pollut. R. 21 (6), 4236, 2014.

12. MA L.M., ZHANG X. The spatial effect of China's haze pollution and the impact from economic change and energy structure. China. Ind. Econ. 4, 19, 2014. (In Chinese)

13. BAEK J. A new look at the FDI-income-energy-environment nexus: dynamic panel data analysis of ASEAN. Energ. Policy. 91, 22, 2016.

14. HUEBLER M., KELLER A. Energy savings via FDI? Empirical evidence from developing countries. Environ. Dev. Econ. 15 (1), 59, 2010. 
15. LI K., QI S. Does FDI increase industrial energy consumption of china? Based on the empirical analysis of Chinese provinces industrial panel data. Emerg. Mark. Financ. Tr. 52 (6), 1305, 2016.

16. HE J. Pollution haven hypothesis and environmental impacts of foreign direct investment: the case of industrial emission of sulfur dioxide $\left(\mathrm{SO}_{2}\right)$ in Chinese provinces. Ecol. Econ. 60 (1), 228, 2006.

17. ELLIOTT R.J.R., SUN P., CHEN S. Energy intensity and foreign direct investment: a Chinese city-level study. Energ. Econ. 40, 484, 2013.

18. WANG S.B., XU Y.Z. Environmental regulation and haze pollution decoupling effect: based on the perspective of enterprise investment preferences. China. Ind. Econ. 4, 18, 2015 [In Chinese].

19. GROSSMAN G.M., KRUEGER A.B. Economic growth and the environment. Q. J. Econ. 110 (2), 353, 1995.
20. PENG Y.X., HE H.H. Research on the relationship of energy consumption and economic development in Guangdong province. China. Popul. Resour. Environ. 25 (11), 69, 2015 [In Chinese].

21. HU Z.Y., LIU Y.W. Spatial econometric analysis of energy consumption, pollution emission, regional economic development. J. Appl. Stat. Manage. 34 (1), 1, 2015 [In Chinese].

22. ANSELIN L. Spatial econometrics: methods and models. Kluwer. Academic. Publishers. Dordrecht. 1988.

23. ANSELIN L. Local indicators of spatial association-LISA. Geogr. Anal. 27 (2), 93, 1995.

24. ANSELIN L. Under the hood Issues in the specification and interpretation of spatial regression models. Agr. EconBlackwell. 27 (3), 247, 2002.

25. ELHORST J.P. Specification and estimation of spatial panel data models. Int. Regional. Sci. Rev. 2 (26), 244, 2003. 